\title{
Synthesis, antifungal activity of caffeic acid derivative esters, and their synergism with fluconazole and nystatin against Candida spp.
}

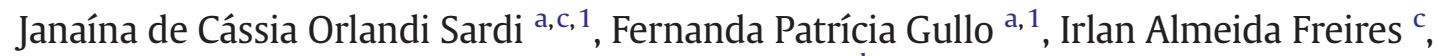 \\ Nayla de Souza Pitangui a , Maicon Petrônio Segalla b, Ana Marisa Fusco-Almeida a , Pedro Luiz Rosalen ${ }^{\text {c }}$, \\ Luís Octávio Regasini ${ }^{\text {b,d }}$, Maria José Soares Mendes-Giannini ${ }^{\text {a,* }}$ \\ a Department of Clinical Analysis, Laboratory of Clinical Mycology, Faculty of Pharmaceutical Sciences, UNESP-Univ Estadual Paulista, Araraquara, SP14801-902, Brazil \\ ${ }^{\mathrm{b}}$ Department of Biochemistry and Chemical Technology, Institute of Chemistry, UNESP-Univ Estadual Paulista, Araraquara, SP14800-060, Brazil \\ c Department of Physiological Sciences, Piracicaba Dental School, University of Campinas, Piracicaba, SP13414-90, Brazil \\ ${ }^{d}$ Department of Chemistry and Environmental Sciences, Institute of Biosciences, Letters and Exact Sciences, São José do Rio Preto, SP15054-000, Brazil
}

\section{A R T I C L E I N F O}

\section{Article history:}

Received 7 March 2016

Received in revised form 11 July 2016

Accepted 5 August 2016

Available online 8 August 2016

\section{Keywords:}

Synergism

Candida albicans

Caffeic acid

Antifungal

\begin{abstract}
A B S T R A C T
We tested the antifungal potential of caffeic acid and 8 of its derivative esters against Candidaalbicans ATCC 90028 and 9 clinical isolatesand carried out a synergism assay with fluconazole and nystatin. Propyl caffeate (C3) showed the best antifungal activity against the tested strains. When in combination, $\mathrm{C} 3$ markedly reduced the MIC of fluconazole and nystatin with synergistic effect up to 64-fold. Finally, C3 showed a high $\mathrm{IC}_{50}$ value and selective indexagainst oral keratinocytes, demonstrating low toxicity against this cell type and selectivity for yeast cells. Further research should confirm its antifungal potential for development of combined therapy to treat C. albicans infections.
\end{abstract}

(c) 2016 Elsevier Inc. All rights reserved.

\section{Introduction}

Oral candidiasis is one of the most common opportunistic infections afflicting humans, with Candida albicans as the major causative agent of this disease (Garcia-Cuesta et al., 2014). The complexity of interactions between Candida and other microorganisms in the host, mainly bacteria, suggest that several mechanisms are involved in yeast fitness to the oral cavity. Some studies have shown that Candida spp. can coaggregate with bacteria in dental plaque. This feature may be an important factor for the onset of oral candidiasis as well as fungal colonization of carious cavities and periodontal pockets (Sardi et al., 2012; Thurnheer et al., 2015). The presence of yeasts in subgingival regions may contribute to the pathogenesis of periodontal disease or increase the chance of candidemia, especially in cases of immunosuppression (Al Mubarak et al., 2013; Hannula et al., 2001; Reynaud et al., 2001). In addition, it has been well documented that systemic diseases such as diabetes and AIDS; physiological conditions such as pregnancy, infancy, or old age; nutritional factors; treatment with broad-spectrum antibiotics; use of immunosuppressive drugs and corticosteroids;

\footnotetext{
* Corresponding author. Tel: +55-16-3301-5716.

E-mail addresses: janasardi@gmail.com (J.C.O. Sardi), gianninimj@gmail.com (M.J.S. Mendes-Giannini).

1 These authors contributed equally to this work.
}

xerostomia, and use of dentures may predispose the individual to develop candidiasis (Manfredi et al., 2006; Soll, 2002; Tekeli et al., 2004).

The current therapy with antifungals has serious drawbacks, in particular due to toxic effects to human cells and adverse effects (Epstein et al., 2002; Gabler et al., 2008). As the drugs used to treat candidiasis are not always specific and properly prescribed (targeting the causative agent of infection), there has been a significant increase in resistance of Candida spp. to traditional antifungal drugs. The increasing microbial resistance rates may also be a result of long-term drug exposure or selection of strains with intrinsic resistance mechanisms (Fernandez-Ruiz et al., 2015; Freitas et al., 2015; Liao et al., 2015; Seifi et al., 2015; Ying et al., 2013). Therefore, the development of novel strategies to minimize the toxic effects of current antifungals and improve their effectiveness has been strongly encouraged.

Natural products have continued to be a rich source of new drugs with clinically significant biological targets. Over the past 34 years, 49\% of Food and Drug Administration-approved chemotherapeutic drugs were either natural products or directly derived therefrom (Newman and Cragg, 2016). There is a great interest of the pharmaceutical industry in the discovery of new molecules of natural origin or even their combination with existing drugs,to improve efficacy, potency, safety, tolerabilityand decrease production costs, side effects, and selection of resistant strains (Svetaz et al., 2016). A number of studies in the literature have established the value of combined antifungal therapy 
against resistant strains, in particular standard drugs with naturallyoccurring agents (Han et al., 2016; Pippi et al., 2015).

Caffeic acid (3,4-dihydroxycinnamic acid) is an important phenolic compound commonly found in plants, foods, and propolis samples, particularly in the form of caffeic acid phenethyl ester(Paracatu et al., 2014; Rzepecka-Stojko et al., 2015). It is better known for its pharmacological properties, including antimicrobial, antioxidant, anti-inflammatory, and anticancer (Balachandran et al., 2012; Kuo et al., 2015). Nevertheless, modifications of the caffeic acid structure into esters or amides, for instance, may generate novel analog molecules with enhanced and desired biological activity (Touaibia et al., 2011), particularly as antimicrobials (Fu et al., 2010).

Herein, we investigated the antifungal potential of caffeic acid and 8 of its derivative esters against C. albicans ATCC 90028 and 9 oral clinical isolates. The most active molecule, propyl caffeate (C3), was selected for a synergism assay with fluconazole and nystatin against the $C$. albicans strainsand tested for its toxicity on oral keratinocytes (NOK cells).

Table 1

Nomenclature, molecular formulas, and the chemical structures of the caffeic acid derivative esters tested in this study.

\begin{tabular}{|c|c|c|c|}
\hline Code & Nomenclature & Molecular formula & Chemical structure \\
\hline $\mathrm{CO}$ & Caffeic acid & $\mathrm{C}_{9} \mathrm{H}_{8} \mathrm{O}_{4}$ & Caffeic acid \\
\hline $\mathrm{C} 1$ & Methyl caffeate & $\mathrm{C}_{10} \mathrm{H}_{8} \mathrm{O}_{4}$ & Methyl caffeate \\
\hline $\mathrm{C} 2$ & Ethyl caffeate & $\mathrm{C}_{11} \mathrm{H}_{12} \mathrm{O}_{4}$ & Ethyl caffeate \\
\hline $\mathrm{C} 3$ & Propyl caffeate & $\mathrm{C}_{12} \mathrm{H}_{14} \mathrm{O}_{4}$ & Propyl caffeate \\
\hline $\mathrm{C} 4$ & Butyl caffeate & $\mathrm{C}_{13} \mathrm{H}_{16} \mathrm{O}_{4}$ & Butyl caffeate \\
\hline $\mathrm{C} 5$ & Pentyl caffeate & $\mathrm{C}_{14} \mathrm{H}_{18} \mathrm{O}_{4}$ & Pentyl caffeate \\
\hline C6 & Hexyl caffeate & $\mathrm{C}_{15} \mathrm{H}_{20} \mathrm{O}_{4}$ & Hexyl caffeate \\
\hline C7 & Heptyl caffeate & $\mathrm{C}_{16} \mathrm{H}_{22} \mathrm{O}_{4}$ & Heptyl caffeate \\
\hline $\mathrm{C} 8$ & Octyl caffeate & $\mathrm{C}_{17} \mathrm{H}_{24} \mathrm{O}_{4}$ & Octyl caffeate \\
\hline
\end{tabular}

Table 2

Antifungal activity of caffeic acid derivative esters against C.albicans ATCC 90028.

\begin{tabular}{ccc}
\hline \multirow{2}{*}{ Caffeic acid derivates } & \multicolumn{2}{l}{ C.albicans ATCC 90028} \\
\cline { 2 - 3 } & MIC $(\mu \mathrm{g} / \mathrm{mL}) \mathrm{MFC}(\mu \mathrm{g} / \mathrm{mL})$ & 125 \\
\hline C0 & 125 & 125 \\
C1 & 125 & 31.25 \\
C2 & 31.25 & 15.62 \\
C3 & 15.62 & 15.62 \\
C4 & 15.62 & 31.25 \\
C5 & 31.25 & 7.81 \\
C6 & 7.81 & 31.25 \\
C7 & 31.25 & 31.25 \\
C8 & 31.25 & 4.0 \\
Nystatin & 4.0 & 0.5 \\
Fluconazole & 0.5 & \\
\hline
\end{tabular}

\section{Materials and methods}

\subsection{Synthesis of esters}

Caffeic acid $(0.2 \mathrm{mmol} / \mathrm{L})$ solution and corresponding alcohols (20 mmol/L) were prepared at $5{ }^{\circ} \mathrm{C}$ with a solution of $N, N^{\prime}-$ dicyclohexylcarbodiimide $(1.0 \mathrm{mmol} / \mathrm{L})$ in $p$-dioxane $(3.0 \mathrm{~mL})$. After the solution was stirred for $48 \mathrm{~h}$, the solvent was removed under reduced pressure. The residue was partitioned 3times with EtOAc and filtered. The filtrate was serially washed with saturated aqueous citric acid solution (3 times), saturated aqueous $\mathrm{NaHCO}_{3}$ (3times), water (2times), dried over $\mathrm{MgSO}_{4}$, and evaporated under reduced pressure. The crude products were purified over a silica gel column using an isocratic system of $\mathrm{CHCl}_{3}-\mathrm{MeOH}$ (98:2). The modifications made in caffeic acid molecule are shown in Table 1.

\subsection{Microorganisms}

C.albicans ATCC 90028 strain and 9 highly virulent clinical isolates of C. albicans obtained from the oral cavity of patients with diabetics and periodontitis (Sardi et al., 2012) were used in this study. This study was approved by the research ethics committee at Piracicaba Dental School, University of Campinas, Piracicaba, SP, Brazil (protocol no. 062/2008).

\subsection{Determination of antifungal activity}

TheMICof caffeic acid and its 8 derivatives against $C$. albicans ATCC 90028 was determined using 96 -well microplates based on the protocol M27-A3 of the CLSI (2008), with modifications. The esters that showed the lowest MIC values against C. albicans ATCC 90028 (C3, C4, and C6) were then tested against 9 clinical isolates of $C$. albicans. The synthetic compounds of caffeic acid were diluted in DMSO and tested in concentrations ranging from 250to $0.48 \mu \mathrm{g} / \mathrm{mL}$ (Scorzoni et al., 2007). The inoculum was prepared ( $\lambda 530 \mathrm{~nm}$, Abs 0.08-0.1) and diluted to $2.5 \times 10^{3} \mathrm{CFU} / \mathrm{mL}$. The plates were incubated at $35^{\circ} \mathrm{C}$ for $24 \mathrm{~h}$. The $\mathrm{MIC}_{100}$ was determined as the lowest concentration of the compound inhibiting visible fungal growth as indicated by $0.1 \%$ resazurin (SigmaAldrich, StLouis, MO, USA). Aliquots from the wells corresponding to the MIC and higher concentrations were subcultured on Sabouraud dextrose agar (Difco®, Detroit, MI, USA) for determination of the minimum fungicidal concentration (MFC). The MFC was defined as the lowest concentration of the compound causing no visible growth on the agar plate.

\subsection{Combinatorial antifungal activity (synergism assay)}

The ester which showed the best activity against $C$. albicans strains (C3) was combined with conventional antifungals commonly used for the treatment of candidiasis, fluconazole and nystatin. Their 
Table 3

Antifungal activity of caffeic acid derivative esters (C3, C4, and C6) against 9 oral clinical isolates of C.albicans.

\begin{tabular}{|c|c|c|c|c|c|c|c|c|c|c|}
\hline \multirow{2}{*}{ C. albicans clinical isolates } & \multicolumn{2}{|l|}{$\mathrm{C} 3$} & \multicolumn{2}{|l|}{ C4 } & \multicolumn{2}{|l|}{ C6 } & \multicolumn{2}{|c|}{ Fluconazole } & \multicolumn{2}{|c|}{ Nystatin } \\
\hline & MIC & MFC & MIC & MFC & MIC & MFC & MIC & MFC & MIC & MFC \\
\hline Ca\#22 & 7.81 & 7.81 & 31.25 & 31.25 & 7.81 & 7.81 & 8.0 & 8.0 & 8.0 & 8.0 \\
\hline $\mathrm{Ca} \# 25$ & 31.25 & 31.25 & 62.50 & 62.50 & 125 & 125 & 8.0 & 8.0 & 8.0 & 8.0 \\
\hline Ca\#45 & 15.62 & 15.62 & 31.25 & 31.25 & 125 & 125 & 8.0 & 8.0 & 8.0 & 8.0 \\
\hline Ca\#50 & 31.25 & 31.25 & 125 & 125 & $>250$ & $>250$ & 2.0 & 2.0 & 4.0 & 4.0 \\
\hline Ca\#61 & 31.25 & 31.25 & 62.50 & 62.50 & $>250$ & $>250$ & 0.5 & 0.5 & 8.0 & 8.0 \\
\hline Ca\#62 & 7.81 & 7.81 & 31.25 & 31.25 & 7.81 & 7.81 & 8.0 & 8.0 & 8.0 & 8.0 \\
\hline Ca\#63 & 31.25 & 31.25 & 62.50 & 62.50 & $>250$ & $>250$ & 8.0 & 8.0 & 8.0 & 8.0 \\
\hline Ca\#105 & 31.25 & 31.25 & 125 & 125 & $>250$ & $>250$ & 8.0 & 8.0 & 8.0 & 8.0 \\
\hline Ca\#124 & 62.50 & 62.50 & 125 & 125 & $>250$ & $>250$ & 4.0 & 4.0 & 8.0 & 8.0 \\
\hline
\end{tabular}

MIC/MFC values are expressed in micrograms per milliliter.

combinatorial antifungal activity was determined through the checkerboard method using 96-well microplates (Dai et al., 2015). A mathematical calculation was used to generate the fractional inhibitory concentration index $(\mathrm{FICI})$, as follows: $\mathrm{FICI}=(\mathrm{MIC}$ compound 1 in combination/MIC compound 1 alone) + (MIC compound 2 in combination/ MIC compound 2 alone). The combinations were classified as synergistic $(\mathrm{FICl} \leq 0.5)$, additive $(0.5<\mathrm{FICl} \leq 1.0)$, indifferent $(1.0<\mathrm{FICl}<4.0)$, and antagonistic ( $\mathrm{FICI} \geq 4.0$ ) (Soares et al., 2014).

\subsection{Cytotoxic effects on oral keratinocytes}

The most active ester derivative (C3) as well as fluconazole and nystatin were tested for their cytotoxicity against keratinocytes from the oral mucosa of humans (NOK cells) provided by the Department of Medicine at Harvard Medical School (DrKarl Munger). NOK cells were maintained in culture medium for keratinocytes without fetal bovine serum (Gibco; Life Technologies) at $36.5{ }^{\circ} \mathrm{C}$ and $5 \% \mathrm{CO}_{2}$. Cells were seeded onto a 96-well plate at a density of $5 \times 10^{4}$ cells/well for $24 \mathrm{~h}$. Then, the cells were exposed to the treatments ( $\mathrm{C} 3$, fluconazole, nystatin, and their combinations) for $24 \mathrm{~h}$. Cell viability was determined by adding aliquots of $10 \mu \mathrm{L}$ of MTT solution ( $5 \mathrm{mg} / \mathrm{mL}$ ) (Sigma-Aldrich) to each well. The plates were incubated at $37^{\circ} \mathrm{C}$ for $4 \mathrm{~h}$ to allow for visualization of precipitated formazan crystals. Aliquots of $100 \mu \mathrm{L}$ of isopropyl alcohol were added per well, and absorbance was read using a spectrophotometer at $560 \mathrm{~nm}$ (Mosmann et al., 1983). Hydrogen peroxide (10\%) was used as a positive control for cytotoxicity, and untreated cells were considered as the negative control. Based on this cell viability assay, we next determined the half maximal inhibitory concentration $\left(\mathrm{IC}_{50}\right)$ for the esters, standarddrugs, and their combinations. The $\mathrm{IC}_{50}$ was defined as the effective concentration of the compound able to inhibit 50\% of the NOK cells. The establishment of this concentration was essential to calculate the selectivity index ( $\mathrm{SI})\left(\mathrm{IC}_{50} / \mathrm{MIC}\right.$ ratio), which was used as an indicator of potential toxicity against normal cells lines at the effective therapeutic concentration for each strain. Hence, theSlindicated the relationship between drug toxicity against $C$. albicans and the host cells (Gullo et al., 2012; Mora-Navarro et al., 2016).

\subsection{Statistical analysis}

All assays were performed in triplicate of independent experiments. The data were analyzed on Graphpad Prism 5.0 (San Diego, CA, USA) by 1 -way analysis of variancefollowed by Bonferroni's multiple comparison test, with a significance level of $5 \%$.

\section{Results}

\subsection{Structure-activity relationship of caffeic acid derivatives}

A screening for antifungal activity of caffeic acid and eight derivative esters against $C$. albicans was carried out. These esters differ by the number of constituent carbons in the molecule, as shown in Table 1. Caffeic acid and all of its synthesized derivatives showed a fungicidal activity against C. albicans ATCC 90028 and presented a structure-activity relationship. As seen in Table 2, the caffeic acid molecule (CO) without structural change and the derived C1 showed MIC and MFC values of $125 \mu \mathrm{g} / \mathrm{mL}$. The derivatives C2, C5, C7, and C8 showed MIC and MFC values of $31.25 \mu \mathrm{g} / \mathrm{mL}$. C3 and C4 showed strong fungicidal activity against C. albicans ATCC 90028, with MIC and MFC values of $15.62 \mu \mathrm{g} / \mathrm{mL}$, together with C6 which showed MIC and MFC equal to $7.81 \mu \mathrm{g} / \mathrm{mL}$. Thus, the compounds C3, C4, and C6-which were better than their originating caffeic acid molecule-were further tested against 9 oral clinical isolates of $C$. albicans. As shown in Table 3, the compound C3 demonstrated the best activity when compared with the other caffeic acid derivatives (C4 and C6), with MIC and MFC values ranging from 7.81 to $62.5 \mu \mathrm{g} / \mathrm{mL}$. The MIC and MFC of C4 and C6 ranged from 31.25 to $125 \mu \mathrm{g} / \mathrm{mL}$ and 7.81 to $\geq 250 \mu \mathrm{g} / \mathrm{mL}$, respectively.

Table 4

Antifungal effects of propyl caffeate (C3) combined with fluconazole and nystatin against C.albicans ATCC 90028 and 9 oral clinical isolates.

\begin{tabular}{|c|c|c|c|c|c|c|c|c|}
\hline \multirow{2}{*}{ C. albicans strains } & \multicolumn{3}{|l|}{$\mathrm{FCZ}+\mathrm{C} 3$} & \multirow[b]{2}{*}{ Effect/potentiation FCZ } & \multicolumn{4}{|l|}{$\mathrm{NYST}+\mathrm{C} 3$} \\
\hline & $\mathrm{FCZ}(\mathrm{MIC})$ & C3 (MIC) & $\mathrm{FICI}$ & & NYST (MIC) & C3 (MIC) & FICI & Effect/potentiation NYST \\
\hline ATCC 90028 & 0.25 & 0.12 & 0.50 & Synergistic/2× & 0.125 & 7.81 & 0.53 & Additive/32× \\
\hline Ca\#22 & 0.125 & 15.62 & 2.01 & Indifferent $/ 64 \times$ & 0.125 & 15.62 & 2.01 & Indifferent/64× \\
\hline $\mathrm{Ca} \# 25$ & 0.5 & 0.12 & 0.06 & Synergistic/16× & 4.0 & 31.25 & 1.50 & Indifferent/2× \\
\hline $\mathrm{Ca} \# 45$ & 1.0 & 0.12 & 0.13 & Synergistic/8x & 0.5 & 15.62 & 1.06 & Indifferent/16x \\
\hline $\mathrm{Ca} \# 50$ & 0.5 & 3.90 & 0.37 & Synergistic/4× & 0.5 & 3.90 & 0.24 & Synergistic/8× \\
\hline Ca\#61 & 0.25 & 0.12 & 0.50 & Synergistic/2× & 0.125 & 31.25 & 1.01 & Indifferent/64× \\
\hline $\mathrm{Ca} \# 62$ & 0.125 & 15.62 & 2.01 & Indifferent $/ 64 \times$ & 0.125 & 15.62 & 2.01 & Indifferent/64x \\
\hline Ca\#63 & 1.0 & 1.95 & 0.18 & Synergistic/8× & 0.125 & 15.62 & 0.51 & Additive $/ 64 \times$ \\
\hline Ca\#105 & 0.5 & 0.48 & 0.07 & Synergistic/16× & 0.25 & 31.25 & 1.03 & Indifferent/32x \\
\hline Ca\#124 & 0.5 & 0.12 & 0.12 & Synergistic/8× & 0.25 & 15.62 & 0.28 & Synergistic/32× \\
\hline
\end{tabular}

MIC values are expressed in micrograms per milliliter.

C3 = propyl caffeate; FCZ = fluconazole; NYST = nystatin. 
Table 5

$\mathrm{IC}_{50}$ value and SIof propyl caffeate, fluconazole, and nystatinshowing the toxicity of the compounds against yeasts in relationship to human oral keratinocytes (NOK cells).

\begin{tabular}{cllc}
\hline Compound & $\mathrm{IC}_{50}(\mu \mathrm{g} / \mathrm{mL})$ & SI (alone) & SI (combination) \\
\hline C3 & 420 & 13.5 & $26.9(\mathrm{FCZ}) / 13.5($ NYST $)$ \\
FCZ & 320 & 40 & 320 \\
NYST & 400 & 50 & 100 \\
\hline
\end{tabular}

\subsection{Combinatorial antifungal activity with standard drugs}

Given the strong antifungal activity of C3 against $C$. albicans strains, we next investigated its combinatorial activity with the standard drugs fluconazole and nystatin. A synergistic activity was observed for the combination between $\mathrm{C} 3$ and fluconazole against most strains, with FICI values ranging from 0.06 to 0.5 . Indifferent activity was observed against 2 clinical isolates, with FICI values close to 2.0. When comparing the MIC values of C3 and fluconazole alone and combined, we observed a decrease in their MIC and potentiation of fluconazole of 2 - to 64-fold (Table 4). The combination of $\mathrm{C} 3$ with nystatin was advantageous (synergistic) against 2 of the 10 strains when compared with the MIC values of the compounds tested alone, with potentiation of nystatin by 8 - to 32 -fold. Additive activity was observed against 1 clinical isolate and C. albicans ATCC 90028 strain, with FICI values ranging from 0.51 to 0.53 . The additive activity of the combination showed potentiation of nystatin between 32 - and 64-fold.

\subsection{Toxic effects on oral keratinocytes}

A viability assay was carried out to evaluate the toxicity of $\mathrm{C} 3$ and standard drugs alone and in combination, against NOK cells. The antifungal compound $\mathrm{C} 3$ showed low toxicity at the tested concentrations, with a high $\mathrm{IC}_{50}$ value of $420 \mu \mathrm{g} / \mathrm{mL}$. Likewise, fluconazole and nystatin showed high $\mathrm{IC}_{50}$ values of $320 \mu \mathrm{g} / \mathrm{mL}$ and $400 \mu \mathrm{g} / \mathrm{L}$, respectively. When combined, both C3 and the antifungals had their SI value increased, indicating selectivity for yeasts rather than NOK cells (Table 5).

Fig. 1 shows the percentage of cell viability of NOK cells treated with the antifungal compounds at different concentrations. The data showed that treatment with $\mathrm{C} 3$, fluconazole, and nystatin maintained over $80 \%$ cell viability at all tested concentrations. Hydrogen peroxide, used as a positive control, markedly affected cell viability, with a significant difference when compared to $\mathrm{C} 3$ and standard drugs $(P<0.05)$.

\section{Discussion}

Opportunistic infections caused by Candida spp. have still been considered a recurrent health issue with high burden worldwide (Denning and Gugnani, 2015; Rodriguez-Tudela et al., 2015). Thus, novel

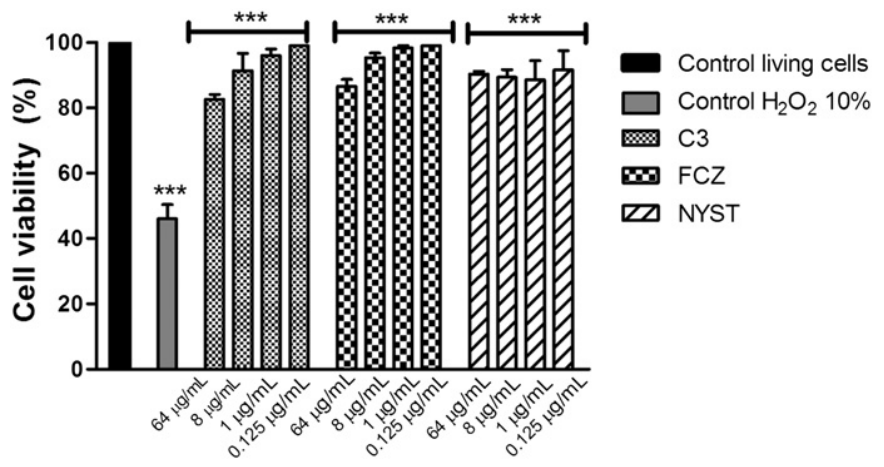

Fig. 1. Representation of the viability of oral mucosa keratinocytes (NOK cells) after treatment with the ester derivative of caffeic acid (C3), fluconazole and nystatin. Statistical analysis was performed by GraphPad Prism software 5.0v, One way ANOVA with Bonferroni post-test's multiple comparison test. ${ }^{* * *} \mathrm{P}<0.05$. therapeutic approaches are much needed to treat Candida infections, including the use of naturallyoccurring agents. In this study, we demonstrate the antifungal potential of caffeic acid derivatives against C. albicans and their successful synergism with antifungals commercially available.

Caffeic acid is commonly found in fruits (Balachandran et al., 2012) and propolis samples (Freires et al., 2016) used in daily life products and folk medicine. We showed that caffeic acid molecule has fungicidal activity against $C$. albicans ATCC 90028 . Nevertheless, the structural modifications performed in this study rendered the caffeic acid molecule much more effective in terms of fungicidal activity, showing a structure-activity relationship. The addition of 2-8 carbon atoms in the caffeic acid molecule increased its anti-Candida activity. Other studies have also demonstrated the relationship between the number of carbons and the antifungal activity of the molecule (Nihei et al., 2003; Soares et al., 2014). Among the synthesized compounds, C3 showed better activity when compared with other caffeic acid derivatives ( $\mathrm{C} 4$ and C6), showing lower minimum inhibitory and fungicidal concentrations against most strains. Balachandran et al. (2012) isolated methyl caffeate from Solanum torvum plant and showed antibacterial activity against Gram-negative and Gram-positive bacteria, in addition to antifungal activity against $C$. albicans and Apergillus flavus. These findings confirm the antimicrobial potential of caffeic acid derivatives.

Of note, the clinical isolates used in this study showed lower susceptibility to nystatin and fluconazole when compared with the reference strain of $C$. albicans ATCC 90028. This could be due to acquisition of resistance mechanisms as the isolates belonged to diabetic patients. A recent study showed that this group of patients is prone to develop Candida infections in cases of poor glycemic control (Zomorodian et al., 2016).

Microbial resistance has raised concern over the last decades as the investment in antibiotic discovery is declining considerably over time when compared to high-priced drugs such as chemotherapeutics (Bax and Green, 2015). To make it worse, failure in prescribing the appropriate drug, misuse, and long hospital stay have led to the emergence of azole-resistant isolates, particularly in cases of invasive infections (Liao et al., 2015; Sanguinetti et al., 2015). This opens avenues for the development of combined antifungal therapy, in which drugs with different mechanisms of action (or not) are combined to enhance their antifungal potency and avoid selection of resistant strains. Here, we demonstrated the successful combination of propyl caffeate (C3) with fluconazole and nystatin against $C$. albicans strains. A study performed by Han and Lee (2005) demonstrated the synergistic effect of the combination between amphotericin B and berberine (alkaloid) against C. albicans. These authors also tested this combination in mice with candidemia and observed that the combined treatment prolonged the lives of mice in 22 days compared to those treated with amphotericin $B$ alone. Other studies have reported the successful combination of essential oils with conventional drugs, including nystatin, fluconazole, and micafungin (Aprotosoaie et al., 2008; Rodrigues et al., 2012; Rosato et al., 2009; Stringaro et al., 2014).

With the purpose of future clinical use, we also investigated the effects of $\mathrm{C} 3$ against oral keratinocytes and compared them with those of the standard drugs. NOK cells were chosen for this study as they constitute the main epithelial cell type lining the oral mucosa, which would be highly exposed in case of administration of an oral suspension or a solution for oral candidiasis. Overall, low toxicity was found for $\mathrm{C} 3$, fluconazole, and nystatin, with $\mathrm{IC}_{50}$ values higher than their MIC/MFC. These agents also showed a high SI value, which means that, if the index is greater than 10.0, the compound exhibits selectivity for killing yeasts rather than the host's cells. The combination between $\mathrm{C} 3$ and fluconazole led to a considerable increase in their SIs, highlighting their selectivity for yeast cells.

Collectively, our findings indicate that the propyl ester modification of caffeic acid molecule (C3) has strong fungicidal activity and potentiated the effects of fluconazole and nystatin against $C$. albicans strains, with little effects against oral keratinocytes. Further studies should 
focus on the effects of these combinations against Candida biofilms and establish C3 mechanism(s) of action.

The authors declare no conflict of interest.

\section{Acknowledgments}

The authors thank the National Council for Scientific and Technological Development (CNPq, Brazil; Grant No. 474335/2013-5) for financial support.

\section{References}

Al Mubarak S, Robert AA, Baskaradoss JK, Al-Zoman K, Al Sohail A, Alsuwyed A, et al. The prevalence of oral Candida infections in periodontitis patients with type 2 diabetes mellitus. J Infect Public Health 2013;6:296-301.

Aprotosoaie AC, Hăncianu M, Poiată A, Tuchiluș C, Spac A, Cioană O, et al. In vitro antimicrobial activity and chemical composition of the essential oil of Foeniculum vulgare Mill. Rev Med Chir Soc Med Nat Iasi 2008;112:832-6.

Balachandran C, Duraipandiyan V, Al-Dhabi NA, Balakrishna K, Kalia NP, Rajput VS, et al. Antimicrobial and Antimycobacterial activities of methyl caffeate isolated from Solanum torvum Swartz. Fruit Indian J Microbiol 2012;52:676-81.

Bax R, Green S. Antibiotics: the changing regulatory and pharmaceutical industry paradigm. J Antimicrob Chemother 2015;70:1281-4.

Clinical and Laboratory Standards Institute (CLSI). Protocol M27-A3. Reference method for broth dilution antifungal susceptibility testing of yeasts. 3rd ed. Pennsylvania: CLSI; 2008.

Dai L, Zang C, Tian S, Liu W, Tan S, Cai Z, et al. Design, synthesis, and evaluation of caffeic acid amides as synergists to sensitize fluconazole-resistant Candida albicans to fluconazole. Bioorg Med Chem Lett 2015;25:34-7.

Denning DW, Gugnani HC. Burden of serious fungal infections in Trinidad and Tobago. Mycoses 2015;58:80-4.

Epstein JB, Dawson JR, Buivids IA, Wong B, Le ND. The effect of a disinfectant/coolant irrigant on microbes isolated from dental unit water lines. Spec Care Dentist 2002;22:137-41.

Fernández-Ruiz M, Puig-Asensio M, Guinea J, Almirante B, Padilla B, Almela M, et al. Candida tropicalis bloodstream infection: incidence, risk factors and outcome in a population-based surveillance. J Infect 2015;71:385-94.

Freires IA, Queiroz VC, Furletti VF, Ikegaki M, de Alencar SM, Duarte MC, et al. Chemical composition and antifungal potential of Brazilian propolis against Candida spp. J Mycol Med 2016. http://dx.doi.org/10.1016/j.mycmed.2016.01.003.

Freitas EM, Monteiro LC, Fernandes MB, Martelli Junior H, Bonan PR, Nobre SA. Antifungal susceptibility in vitro determined by the Etest $₫$ for Candida obtained from the oral cavity of irradiated and elderly individuals. Braz Dent J 2015;26:99-104.

Fu J, Cheng K, Zhang Z, Fang R, Zhu H. Synthesis, structure and structure-activity relationship analysis of caffeic acid amides as potential antimicrobials. Eur J Med Chem 2010; 45:2638-43.

Gabler IG, Barbosa AC, Velela RR, Lyon S, Rosa CA. Incidence and anatomic localization of oral candidiasis in patients with AIDS hospitalized in a public hospital in Belo Horizonte, MG, Brazil. J Appl Oral Sci 2008;16:247-50.

Garcia-Cuesta C, Sarrion-Pérez MG, Bagán JV. Current treatment of oral candidiasis: a literature review. J Clin Exp Dent 2014;6:e576-82.

Gullo FP, Sardi JC, Santos VA, Sangalli-Leite F, Pitangui NS, Rossi SA, et al. Antifungal activity of maytenin and pristimerin. Evid Based Complement Alternat Med 2012;2012: 340787.

Han Y, Lee JH. Berberine synergy with amphotericin B against disseminated candidiasis in mice. Biol Pharm Bull 2005;28:541-4.

Han B, Chen J, Yu Y, Cao Y, Jiang Y. Antifungal activity of Rubus chingii extract combined with fluconazole against fluconazole-resistant Candida albicans. Microbiol Immunol 2016;60:82-92.

Hannula J, Dogan B, Slots J, Okte E, Asikainen S. Subgingival strains of Candida albicans in relation to geographical origin and occurrence of periodontal pathogenic bacteria. Oral Microbiol Immunol 2001;16:113-8.

Kuo YY, Jim WT, Su LC, Chung CJ, Lin CY, Huo C, et al. Caffeic acid phenethyl ester is a potential therapeutic agent for oral cancer. Int J Mol Sci 2015;16:10748-66.

Liao X, Qiu H, Li R, Guo F, Liu W, Kang M, et al. Risk factors for fluconazole-resistant invasive candidiasis in intensive care unit patients: an analysis from the China survey of candidiasis study. J Crit Care 2015;30:862.e1-5.
Manfredi M, McCullough MJ, Al-Karaawi ZM, Vescovi P, Porter SR. In vitro evaluation of virulence attributes of Candida spp. isolated from patients affected by diabetes mellitus. Oral Microbiol Immunol 2006;21:183-9.

Mora-Navarro C, Méndez-Vega J, Caraballo-León J, Lee M-r, Palecek S, Torres-Lugo M, et al. Hydrophobicity of antifungal $\beta$-peptides is associated with their cytotoxic effect on in vitrohuman colon Caco-2 and liver HepG2 cells. PLoS One 2016;11(3), e0149271. http://dx.doi.org/10.1371/journal. pone.0149271.

Newman DJ, Cragg GM. Natural products as sources of new drugs over the 30 Years from 1981 to 20140. J Nat Prod 2016. http://dx.doi.org/10.1021/acs.jnatprod.5b01055. [in press].

Nihei K, Nihei A, Kubo I. Rational design of antimicrobial agents: antifungal activity of alk(en)yl dihydroxybenzoates and dihydroxyphenyl alkanoates. Bioorg Med Chem Lett 2003;13:3993-6.

Paracatu LC, Bonacorsi C, de Farias CM, Nazare AC, Petronio MS, Regasini LO, et al. Alkyl caffeates as anti-Helicobacter pylori and scavenger of oxidants produced by neutrophils. Med Chem 2014;10:74-80.

Pippi B, Lana AJD, Moraes RC, Güez CM, Machado M, Oliveira LFS, et al. In vitro evaluation of the acquisition of resistance, antifungal activity and synergism of Brazilian red propolis with antifungal drugs on Candida spp. J Appl Microbiol 2015:118:839-50.

Reynaud AH, Nygaard-Østby B, Bøygard GK, Eribe ER, Olsen I, Gjermo P. Yeasts in periodontal pockets. J Clin Periodontol 2001;28:860-4.

Rodrigues FF, Oliveira LG, Rodrigues FF, Saraiva ME, Almeida SC, Cabral ME, et al. Chemical composition, antibacterial and antifungal activities of essential oil from Cordia verbenacea DC leaves. Pharmacognosy Res 2012;4:161-5.

Rodriguez-Tudela JL, Alastruey-Izquierdo A, Gago S, Cuenca-Estrella M, León C, Miro JM, et al. Burden of serious fungal infections in Spain. Clin Microbiol Infect 2015;21: $183-9$

Rosato A, Vitali C, Piarulli M, Mazzotta M, Argentieri MP, Mallamaci R. In vitro synergic efficacy of the combination of nystatin with the essential oils of Origanum vulgare and Pelargonium graveolens against some Candida species. Phytomedicine 2009;16: 972-5.

Rzepecka-Stojko A, Kabała-Dzik A, Moździerz A, Kubina R, Wojtyczka RD, Stojko R, et al. Caffeic acid phenethyl ester and ethanol extract of propolis induce the complementary cytotoxic effect on triple-negative breast cancer cell lines. Molecules 2015;20:9242-62.

Sanguinetti M, Posteraro B, Lass-Flörl C. Antifungal drug resistance among Candida species: mechanisms and clinical impact. Mycoses 2015;58:2-13.

Sardi JC, Duque C, Höfling JF, Gonçalves RB. Genetic and phenotypic evaluation of Candida albicans strains isolated from subgingival biofilm of diabetic patients with chronic periodontitis. Med Mycol 2012;50:467-75.

Scorzoni L, Benaducci T, Fusco-Almeida AM, Silva DHS, Bolzani VS, Mendes-Giannini MJS. The use of standard methodology for determination of antifungal activity of natural products against medical yeasts Candida sp and Cryptococcus sp. Braz J Microbiol 2007;38:391-7.

Seifi Z, Zarei-Mahmoudabadi A, Zarrin M. Extracellular enzymes and susceptibility to fluconazole in Candida strains isolated from patients with vaginitis and healthy individuals. Jundishapur J Microbiol 2015;8:e20162.

Soares LA, Gullo FP, Sardi Jde C, Pitangui Nde S, Costa-Orlandi CB, Sangalli-Leite F, et al. Anti-trichophyton activity of protocatechuates and their synergism with fluconazole. Evid Based Complement Alternat Med 2014;2014:957860.

Soll DR. Candida commensalism and virulence: the evolution of phenotypic plasticity. Acta Trop 2002:81:101-10.

Stringaro A, Vavala E, Colone M, Pepi F, Mignogna G, Garzoli S, et al. Effects of Mentha suaveolensessential oil alone or in combination with other drugs in Candida albicans. Evid Based Complement Alternat Med 2014;2014:125904.

Svetaz LA, Postigo A, Butassi E, Zacchino SA, Sortino MA. Antifungal drugs combinations: a patent review 2000-2015. Exp Opin Therapeut Patent 2016. http://dx.doi.org/10. 1517/13543776.2016.1146693. [in press].

Tekeli A, Dolapci I, Emral R, Cesur S. Candida carriage and Candida dubliniensis in oropharyngeal samples of type-1 diabetes mellitus patients. Mycoses 2004;47:315-8.

Thurnheer T, Bostanci N, Belibasakis GN. Microbial dynamics during conversion from supragingival to subgingival biofilms in an in vitro model. Mol Oral Microbiol 2015. http://dx.doi.org/10.1111/omi.12108.

Touaibia M, Jean-François J, Doiron J. Caffeic acid, aversatile pharmacophore: an overview. Mini-Rev Med Chem 2011:11:695-713.

Ying Y, Zhao Y, Hu X, Cai Z, Liu X, Jin G, et al. In vitro fluconazole susceptibility of 1,903 clinical isolates of Candida albicans and the identification of ERG11 mutations. Microb Drug Resist 2013;19:266-73.

Zomorodian K, Kavoosi F, Pishdad GR, Mehriar P, Ebrahimi H, Bandegani A, et al. Prevalence of oral Candida colonization in patients with diabetes mellitus. J Mycol Med 2016. http://dx.doi.org/10.1016/j.mycmed.2015.12.008 